\title{
Determinação das Frações Protéicas e de Carboidratos e Taxas de Degradação In Vitro da Cana-de-Açúcar, da Cama de Frango e do Farelo de Algodão ${ }^{1}$
}

\author{
Elzânia Sales Pereira², Augusto César de Queiroz ${ }^{3}$, Mario Fonseca Paulino ${ }^{3}$, Paulo Roberto Cecon 4 , \\ Sebastião de Campos Valadares Filho ${ }^{3}$, Lídia Ferreira Miranda ${ }^{6}$, Alberto Magno Fernandes ${ }^{5}$, \\ Luciano da Silva Cabral ${ }^{5}$
}

\begin{abstract}
RESUMO - O objetivo do presente estudo foi determinar o fracionamento e a cinética de degradação dos compostos nitrogenados e dos carboidratos da cana-de-açúcar, da cama de frango e do farelo de algodão. Para determinação das frações nitrogenadas, foram analisados os compostos nitrogenados não-protéicos, nitrogênio solúvel e insolúvel em tampão borato-fosfato e nitrogênio protéico insolúvel em detergente neutro e em detergente ácido. As taxas de degradação das frações protéicas foram obtidas in vitro, a partir da incubação dos alimentos com proteases isoladas do meio ruminal. Para obtenção do fracionamento dos carboidratos, de acordo com o sistema Cornell, foram calculados os carboidratos totais, as suas frações $\mathrm{C}, \mathrm{B}_{2}$ e os componentes solúveis em detergente neutro. Foram determinadas as frações potencialmente degradável $\left(B_{2}\right)$ e indegradável $(C)$ da fibra em detergente neutro, corrigida para cinzas e proteína, e as taxas de latência dinâmica, de degradação e de crescimento específico dos microrganismos, a partir da fração $B_{2}$, além dos coeficientes de degradabilidade e do efeito de repleção ruminal da FDN dos alimentos. Valores de 71,01; 45,80; e 71,66\% da fração $\mathrm{B}_{2}$ dos compostos nitrogenados foram encontrados para cana-de-açúcar, cama de frango e farelo de algodão, respectivamente. A cama de frango destacou-se pela maior fração $\mathrm{B}_{3}$ e C $(23,57$ e $10,11 \%)$. As taxas de degradação da fração $\mathrm{B}_{3}$ foram 0,$03 ; 0,031$; e $0,09 \mathrm{~h}^{-1}$ para cana-de-açúcar, cama de frango e farelo de algodão, respectivamente. A fração C dos carboidratos foi 22,74; 28,00; e 32,64\% para os três alimentos, respectivamente. A cana-de-açúcar apresentou elevada fração de componentes solúveis $(35,99 \%)$, porém mostrou baixa digestão da fração potencialmente degradável $\left(3,41 \% \mathrm{~h}^{-1}\right)$, a qual apresentou significativo efeito de repleção $\left(6,6 \mathrm{~h}^{-1}\right)$. Com estas técnicas, foi possível detectar que alimentos como cana-de-açúcar e cama de frango apresentam baixo valor nutricional para atendimento das exigências dos microrganismos do rúmen e hospedeiro.
\end{abstract}

Palavras-chave: degradação de carboidratos, proteína, rúmen

\section{Determination of the Protein and Carbohydrates Fractions, and In Vitro Degradation Rates of the Sugar Cane, Poultry Litter and Cottonseed Meal}

\begin{abstract}
The objective of the present study was the fractionation and the degradation kinetics of the nitrogenous compounds and of the carbohydrates of the sugar cane, poultry litter and cottonseed meal. The non-protein nitrogenous compounds, soluble and insoluble nitrogen in borate-phosphate buffer, neutral detergent and in acid detergent insoluble protein nitrogen were analyzed for the determination of the nitrogen fractions. The degradation rates of the protein fractions were obtained by the In vitro incubation of the feeds with proteases isolated from ruminal ambient. The total carbohydrates, and its fractions $\mathrm{C}_{2} \mathrm{~B}_{2}$ and the soluble neutral detergent components were calculated for the determination of the carbohydrates using the Cornell system. The potentially degradable $\left(\mathrm{B}_{2}\right)$ and undegradable $(\mathrm{C})$ fractions of the neutral detergent fiber, corrected for ashes and protein, and the lag dynamic rates, of degradation and of specific microbial growth, from the fraction $\mathrm{B}_{2}$, were determined. Besides, the coefficient of degradabilities and of the NDF ruminal repletion effect of the feeds, were also determined. The values of $71.01 ; 45.80$ and $71.66 \%$ of the fraction $\mathrm{B}_{2}$ of the nitrogenous compounds were observed for sugar cane, poultry litter and cottonseed meal, respectively. The poultry litter stood out for the highest $\mathrm{B}_{3}$ and $\mathrm{C}$ fraction (23.57 and $10.11 \%$ ). The $\mathrm{B}_{3}$ fraction degradation rates were of $0.03 ; 0.031$ and $0.09 \mathrm{~h}^{-1}$ for sugarcane, poultry litter and cottonseed meal, respectively. The fraction $\mathrm{C}$ of the carbohydrates varied of $22.74,28.00$ and $32.64 \%$ for the three feeds, respectively. The sugar cane presented high soluble components fraction $(35,99 \%)$, however it presented low digestion of the potentially degradable fiber $\left(3.41 \% \mathrm{~h}^{-1}\right)$ and a significant repletion effect $\left(6,6 \mathrm{~h}^{-1}\right)$. The feeds, sugarcane and poultry litter present low nutritional value to meet the ruminal microorganisms and of the hostess requirements.
\end{abstract}

Key Words: carbohydrate degradation, protein, rumen

\footnotetext{
${ }^{1}$ Parte da tese apresentada à UFV para obtenção do título de "Magister Scientiae". Pesquisa financiada pelo CNPq.

2 Professor do Departamento de Zootecnia - UNIOESTE - PR. E.mail: elzania@unioeste.br

3 Professor do Departamento de Zootecnia da UFV - MG.

${ }^{4}$ Professor do Departamento de Estatística da UFV - MG.

${ }^{5}$ Estudante de Doutorado do Departamento de Zootecnia da UFV - MG.

${ }^{6}$ Estudante de Doutorado do Departamento de Medicina Veterinária e Zootecnia da UFMG - MG.
} 


\section{Introdução}

Nos sistemas usuais de produção, os ruminantes obtêm a maioria dos nutrientes a partir de volumosos. Daí a necessidade da utilização de modelos mecanicistas para descrever o relacionamento entre a composição bromatológica dos alimentos consumidos e a predição do desempenho animal (FOX et al., 1992).

Os alimentos, quando consumidos pelos ruminantes, são transformados pelos microrganismos ruminais, e esta transformação resulta em confundimento para a predição do desempenho animal, a partir dos componentes dietéticos (RUSSELL et al., 1992). Como meio de melhor caracterizar os componentes de um alimento (proteína e carboidratos), SNIFFEN et al. (1992) sugeriram que os compostos nitrogenados fossem subfracionados nas frações A (fração solúvel-NNP), B1 (fração rapidamente degradada no rúmen), B2 (fração insolúvel, com taxa de degradação intermediária no rúmen), B3 (fração insolúvel lentamente degradada no rúmen) e C (fração insolúvel no rúmen e indigestível no trato gastrintestinal). Os carboidratos também podem ser fracionados em componentes A (açúcares solúveis com rápida degradação ruminal), B1 (amido e pectina), B2 (correspondente à fibra potencialmente degradável) e $\mathrm{C}$ (que representa característica de indigestibilidade).

As frações nitrogenadas têm sido determinadas por meio de métodos de solubilização, entretanto, a estimativa de suas respectivas taxas de digestão têm sido obtidas por intermédio de diferentes métodos, resultando em grande variação nos resultados observados. Os métodos in situ e in vitro com proteases oriundas de Streptomyces griseus têm sido os mais utilizados (KRISHNAMOORTHY et al., 1983). A ação das proteases originárias dessa bactéria apresenta atividade máxima para os estudos de degradação protéica em pH 8 (KRISHNAMOORTHY et al., 1983), daí decorrem as críticas com relação ao uso dessas enzimas para obtenção das taxas de degradação (BRODERICK, 1995). Entretanto, mais recentemente, KOHN e ALLEN (1995) propuseram um método in vitro com proteases isoladas dos microrganismos do rúmen, possibilitando a sua utilização para estimativa das taxas de digestão das frações protéicas lentamente digestíveis, sendo, portanto, uma alternativa interessante para o uso das proteases comerciais. Considerando os custos de obtenção, seria adequada a utilização das enzimas isoladas do rúmen, que podem ser obtidas no próprio laboratório (KOHN e ALLEN, 1995; MALAFAIA et al., 1997).
Face ao exposto, o objetivo deste trabalho foi determinar as frações nitrogenadas e de carboidratos, bem como as taxas de degradação das frações protéicas potencialmente degradáveis e dos carboidratos solúveis e insolúveis em detergente neutro, da cana-de-açúcar, da cama de frango e do farelo de algodão.

\section{Material e Métodos}

O fracionamento dos compostos nitrogenados e dos carboidratos e a determinação das taxas de degradação específicas da cana-de-açúcar, da cama de frango e do farelo de algodão foram realizados no Laboratório de Nutrição Animal do Departamento de Zootecnia da Universidade Federal de Viçosa - UFV.

Inicialmente, os alimentos foram analisados para matéria seca (MS), matéria mineral (MM), matéria orgânica (MO), proteína bruta (PB) e extrato etéreo (EE), seguindo o procedimento padrão (ASSOCIATION OF OFFICIAL ANALYTICAL CHEMISTS - AOAC, 1990), e fibra em detergente neutro (FDN) e ácido (FDA) (VAN SOEST et al., 1991). A fração A (NNP) foi determinada pela diferença entre o nitrogênio total e o nitrogênio insolúvel em ácido tricloroacético, o qual foi obtido por intermédio do tratamento de aproximadamente $500 \mathrm{mg}$ da amostra com $50 \mathrm{~mL}$ de água destilada, permanecendo por 30 minutos; posteriormente, foram adicionados $10 \mathrm{~mL}$ de ácido tricloroacético (TCA) a $10 \%$ por 30 minutos (LICITRA et al., 1996). O resíduo remanescente foi filtrado em papel-filtro (Whatman, $\mathrm{n}$ o 54 ), lavado com água e determinado o nitrogênio residual.

O nitrogênio insolúvel total foi determinado a partir do tratamento de $500 \mathrm{mg}$ da amostra com tampão borato-fosfato $\left(\mathrm{NaH}_{2} \mathrm{PO}_{4} \cdot \mathrm{H}_{2} \mathrm{O}\right.$ a $12,2 \mathrm{~g} / \mathrm{L}+$ $\mathrm{Na}_{2} \mathrm{~B}_{4} \mathrm{O}_{7} .10 \mathrm{H}_{2} \mathrm{O}$ a $8,91 \mathrm{~g} / \mathrm{L}+100 \mathrm{~mL} / \mathrm{L}$ de álcool butílico terciário) durante três horas, sendo determinado o $\mathrm{N}$ residual. Pela diferença entre o nitrogênio total e o nitrogênio insolúvel total, foi obtido o nitrogênio solúvel total (NNP + proteína solúvel), do qual foi descontada a fração A, para obtenção da fração B1 (LICITRA et al., 1996).

$A$ fração $B_{3}$ foi calculada pela diferença entre o nitrogênio insolúvel em detergente neutro (NIDN) e o nitrogênio insolúvel em detergente ácido (NIDA), os quais foram determinados por meio da fervura de $500 \mathrm{mg}$ da amostra, com solução detergente neutra e ácida durante uma hora, respectivamente, em que os resíduos foram também analisados para nitrogênio. A 
fração $C$ foi considerada como o nitrogênio insolúvel em detergente ácido (NIDA) e a fração $\mathrm{B}_{2}$, determinada pela diferença entre o nitrogênio total e as frações A, B1, B3 e C (LICITRA et al., 1996).

Para determinação das taxas de degradação ruminal das frações nitrogenadas $\left(\mathrm{B}_{1}, \mathrm{~B}_{2}\right.$ e $\left.\mathrm{B}_{3}\right)$, inicialmente foi realizado o isolamento das enzimas proteolíticas do meio ruminal, a partir dos procedimentos descritos por KOHN e ALLEN (1995). Posteriormente, as taxas de degradação ruminal das frações nitrogenadas potencialmente degradáveis foram determinadas a partir de incubações in vitro (KRISHNAMOORTHY et al., 1983; KOHN e ALLEN, 1995). As amostras em duplicata foram incubadas em erlemeyer por 0,$17 ; 0,33 ; 0,50 ; 0,66$; 1,$5 ; 2,0 ; 3,0 ; 4,0 ; 6,0 ; 8,0,10,0 ; 12,0 ; 18,0 ; 24,0 ; 36,0$; e 48 horas. Foram incubados aproximadamente $8 \mathrm{mg}$ de $\mathrm{N}$ da amostra em erlemeyer, no qual foram adicionados $25 \mathrm{~mL}$ de solução tamponada (constituída de tetraborato de sódio - $\mathrm{Na}_{2} \mathrm{~B}_{4} \mathrm{O}_{7}$ e fosfato de sódio monobásico- $\mathrm{NaH}_{2} \mathrm{PO}_{4} \mathrm{H}_{2} \mathrm{O}$ ) e ajustado $\mathrm{pH}$ para 6,8 , com inoculação de $\mathrm{CO}_{2}$ por 30 minutos, sendos adicionados a esta solução $1,2 \mathrm{~g} / \mathrm{L}$ de $\mathrm{Na}_{2} \mathrm{~S} 9 \mathrm{H}_{2} 0$ e $1,2 \mathrm{~g} / \mathrm{L}$ de $\mathrm{HCl}$ cisteína. Posteriormente, os erlemeyers foram colocados dentro da incubadora, a $39^{\circ} \mathrm{C}$, para estabilização da temperatura; seqüencialmente, $6 \mathrm{~mL}$ de solução contendo as enzimas isoladas do meio ruminal foram adicionados e os erlemeyers, fechados com rolhas tipo bunsen e mantidos em incubadora com mesa de agitação orbital, a $39^{\circ} \mathrm{C}$. Após cada tempo de incubação, os erlemeyers foram retirados da incubadora e todo o seu conteúdo foi transferido quantitativamente para um funil com papel-filtro quantitativo de filtragem rápida, utilizando-se aproximadamente $200 \mathrm{~mL}$ de $\mathrm{H}_{2} \mathrm{O}$ destilada como veículo. Posteriormente, o papel-filtro foi submetido ao processo de digestão em tubo Macro-Kjedahl e, posteriormente, foram feitos procedimentos usuais para determinação do $\mathrm{N}$.

Uma vez obtidos os perfis de degradação da proteína bruta $(\mathrm{PB})$ da cana-de-açúcar, da cama de frango e do farelo de algodão, procedeu-se à interpretação matemática para obtenção das estimativas das taxas de degradação (VIEIRA, 1998), a partir do seguinte modelo: $R(t)=\sum_{i=1}^{3} B_{i} \times \exp \left(-c_{i} \times t\right)+C$, em que $\mathrm{R}(\mathrm{t})$ corresponde ao resíduo de incubação no tempo $\mathrm{t}(\mathrm{h}) ;(\% \mathrm{~PB})$, para $\mathrm{i}=1,2$ e 3 , às frações de proteína verdadeira potencialmente degradáveis; $\mathrm{ci}\left(\mathrm{h}^{-1}\right)$, para $\mathrm{i}=1,2$ e 3 , às taxas de degradação das frações $\mathrm{B}^{\mathrm{i}}$; e
$\mathrm{C}(\% \mathrm{~PB})$, à fração protéica indegradável, representada pela assíntota estabelecida no modelo, quando $\mathrm{t} \rightarrow \infty$ (MALAFAIA e VIEIRA, 1997).

As taxas de degradação das frações foram obtidas após inspeção gráfica do logaritmo natural dos resíduos de incubação da proteína bruta, em função do tempo, para identificação dos diferentes intervalos, em que os pontos não desviaram da linearidade. A identificação desses intervalos permitiu o ajuste dos dados a equações de regressão linear, cujos coeficientes de regressão corresponderam às taxas de degradação das frações protéicas potencialmente degradáveis (VIEIRA, 1998). Assim, foi realizada a seguinte correção nos perfis de degradação: $\operatorname{Ln}[R(t)-C]=\operatorname{Ln}[B(t)]$, em que $R(t)$ corresponde ao resíduo de incubação da proteína bruta da amostra em determinado tempo, t; C, à fração indegradável; e $\mathrm{B}(\mathrm{t})$, ao somatório das frações protéicas potencialmente degradáveis após a incubação das amostras por determinado tempo, $\mathrm{t}$.

A degradabilidade ruminal efetiva das frações foi calculada com base na taxa de passagem hipotética de $0,02 \mathrm{~h}^{-1}$ (AGRICULTURAL AND FOOD RESEARCH COUNCIL - AFRC, 1993), pela seguinte expressão: $\operatorname{DEG}\left(\mathrm{B}_{\mathrm{i}}\right)=\frac{\mathrm{c}_{\mathrm{i}}}{\mathrm{c}_{\mathrm{i}}+\mathrm{k}}$, em que DEG(Bi) corresponde ao coeficiente de digestibilidade da i-ésima fração $B_{i} ; c_{i}\left(h^{-1}\right)$, para $i=1,2$ e 3 , às taxas de degradação das frações $B$; e k, à taxa de passagem das partículas do alimento.

Para obtenção do fracionamento dos carboidratos, conforme o sistema CNCPS, foram determinados os teores de nitrogênio total das amostras (NT), extrato etéreo e matéria mineral (AOAC, 1990). Os carboidratos totais foram determinados pela expressão $\mathrm{CT}=100-(\% \mathrm{~PB}+\% \mathrm{EE}+\% \mathrm{MM})($ SNIFFEN etal., 1992).

Os carboidratos não-estruturais $\left(A+B_{1}\right)$ foram determinados pela seguinte expressão $\mathrm{CNE}=100-\left(\% \mathrm{~PB}+\% \mathrm{EE}+\% \mathrm{FDN}_{\mathrm{CP}}+\mathrm{MM}\right)$, em que $\mathrm{FDN}_{\mathrm{CP}}$ eqüivale à parede celular corrigida para cinzas e proteínas. A fração $\mathrm{C}$ foi obtida por intermédio do resíduo indigestível, após 96 horas de incubação com líquido ruminal e a fração $\mathrm{B}_{2}$, por diferença entre 100 e a FDN remanescente após 96 horas de incubação.

As taxas de degradação específica dos carboidratos da cana-de-açúcar, da cama de frango e do farelo de algodão foram determinadas a partir da técnica de produção cumulativa dos gases (PELL e SCHOFIELD, 1993). Os dados oriundos das frações de carboidratos solúveis e da FDN foram 
interpretados pelo modelo unicompartimental $\mathrm{V}=\mathrm{V}_{\mathrm{f}} /(1+\exp (2-4 * \mathrm{c}(\mathrm{L}-\mathrm{T})))$, em que Vf representa o volume máximo de gás para a respectiva fração; c, a taxa de degradação $\left(\% \mathrm{~h}^{-1}\right) ; \mathrm{L}$, a latência (horas); e T, os tempos de incubação (SCHOFIELD et al., 1994). As taxas de degradação ruminal para as frações de carboidratos CNE e FDN foram estimadas como $\mathrm{m} / \mathrm{V}_{\mathrm{f}}$, em que $\mathrm{m}$ corresponde à taxa máxima de produção de gás. Para realização dos ajustes, usou-se o processo iterativo do algoritmo de Marquadt, utilizando-se o programa SAEG - Sistema de Análises Estatísticas e Genéticas (UNIVERSIDADE FEDERAL DE VIÇOSA - UFV, 1995).

A degradação in vitro da FDN da cana-deaçúcar, da cama de frango e do farelo de algodão foi obtida conforme GONZÁLEZ et al. (1990), utilizando-se tempos de incubação de 3, 6, 9, 12, 24, 36, 72 e 96 horas (MERTENS, 1993). Para a descrição matemática da cinética de degradação da FDN, foi utilizado o modelo logístico decrescente:

$$
\mathrm{R}(\mathrm{t})=\mathrm{U}(0) \times \frac{\mathrm{c}_{2} \times \exp \left(-\mathrm{p}_{2} \times \mathrm{t}\right)-\mathrm{p}_{2} \times \exp \left(-\mathrm{c}_{2} \times \mathrm{t}\right)}{\mathrm{c}_{2}-\mathrm{p}_{2}}+\mathrm{I}(0),
$$

segundo VAN MILGEN et al. (1991), em que R (t) corresponde ao resíduo de incubação; $t$, aos tempos de incubação; $\mathrm{U}(0)$, à fração potencialmente degradável; $\mathrm{c}_{2}\left(\mathrm{~h}^{-1}\right)$, à taxa de degradação de $\mathrm{U}(0) ; \mathrm{I}(0)$, à fração indigestível (\%); e $\mathrm{p}_{2}$, à taxa de latência dinâmica.

O efeito de enchimento ruminal ou repleção ruminal da fração potencialmente degradável $R R(U)$ e da fração indegradável da FDN RR (I) foi determinado conforme VAN MILGEN et al. (1991) pela expressão

$$
\mathrm{RR}=\mathrm{U}_{\mathrm{p}} \times \frac{\mathrm{c}_{2}+\mathrm{p}_{2}+\mathrm{k}}{\left(\mathrm{c}_{2}+\mathrm{k}\right) \times\left(\mathrm{p}_{2}+\mathrm{k}\right)}+\mathrm{I}_{\mathrm{p}} \times \frac{1}{\mathrm{k}},
$$

em que RR, expresso em horas, representa o efeito de enchimento total, $c_{2} ; p_{2}$ e $I_{p}$, os mesmos parâmetros citados anteriormente; e $\mathrm{k}$, a taxa de passagem das partículas do alimento no rúmen.

A taxa de crescimento específico de microrganismos sobre a fração potencialmente degradável $\left(\mathrm{B}_{2}\right)$ dos alimentos foi estimada pela seguinte expressão:

$$
\mu_{\mathrm{m} 2}=\frac{\mathrm{dD}\left(\mathrm{t}_{\mathrm{i}}\right)}{\mathrm{dt}}
$$

em que $\mu_{\mathrm{m}_{2}}\left(\% \mathrm{~h}^{-1}\right)$ corresponde à taxa de crescimento máximo dos microrganismos sobre a fração B2 e ti, à abscissa do ponto de inflecção, estimada de acordo com as expressões descritas por VIEIRA et al. (1997b). Assim, a taxa de crescimento específico pode ser calculada, ao empregar a seguinte definição
(BEUVINK e KOGUT, 1993):

$$
\mathrm{S}_{\mathrm{gr}}=\frac{\mu_{\mathrm{m} 2}}{\mathrm{U}(0)}
$$

em que $\operatorname{Sgr}\left(\mathrm{h}^{-1}\right)$ eqüivale à taxa de crescimento específico dos microrganismos sobre a fração $B_{2}$.

A degradação ruminal da fração potencialmente degradável $\left(\mathrm{B}_{2}\right)$ foi estimada conforme a expressão descrita por VIEIRA et al. (1997b):

$$
\operatorname{DEG}\left(\mathrm{B}_{2}\right)=\frac{\mathrm{c}_{2} \times \mathrm{p}_{2}}{\left(\mathrm{c}_{2}+\mathrm{k}\right) \times\left(\mathrm{p}_{2}+\mathrm{k}\right)}
$$

em que $\operatorname{DEG}\left(\mathrm{B}_{2}\right)$ é o coeficiente de degradação da fração $B_{2}$ dos carboidratos totais; $c_{2}, p_{2}$ e k correspondem aos mesmos parâmetros citados anteriormente.

Os coeficientes de degradação das frações A e $\mathrm{B}_{1}$ foram considerados iguais a 1 , pelo fato de, em geral, a taxa de crescimento específico dos microrganismos sobre estas frações tender a ser muito maior que a taxa de passagem do alimento, mesmo quando se considera a taxa de passagem da fase líquida para a estimativa do escape de frações solúveis (SNIFFEN et al., 1992; NATIONAL RESEARCH COUNCIL - NRC, 1996).

\section{Resultados e Discussão}

A composição bromatológica da cana-de-açúcar, da cama de frango e do farelo de algodão está expressa na Tabela 1. Houve considerável variação nas frações nitrogenadas. A cana-de-açúcar, alimento de baixo teor protéico sob a forma absoluta (Tabela 2), apresentou valores diferenciados sob o aspecto dinâmico obtido por intermédio do fracionamento.

A maior parte dos compostos nitrogenados da cana-de-açúcar, apesar da baixa concentração de $\mathrm{PB}$, encontra-se nas formas de frações $\mathrm{B}_{1}(8,89 \%)$ e $\mathrm{B}_{2}$ $(71,01 \%)$ (Tabela 2$)$, que propiciam disponibilidade de nitrogênio solúvel e peptídeos no rúmen. A biomassa de bactérias ruminais que utilizam carboidratos nãoestruturais pode ser aumentada, quando ocorre adequada disponibilidade da fração $\mathrm{B}_{1}$ no rúmen (RUSSELL et al., 1992); no entanto, a menor proporção de N, na forma de fração $\mathrm{A}$, tem como consequiência baixo suprimento de compostos nitrogenados não-protéicos para microrganismos que fermentam carboidratos estruturais e, conseqüentemente, redução de disponibilidade protéica ao longo do trato gastrintestinal.

Pode-se inferir que concentrados formulados com alimentos que apresentam significativos teores de $\mathrm{N}$ e com maior proporção deste $\mathrm{N}$ nas formas $\mathrm{B}_{1}$ e $\mathrm{B}_{2}$, juntamente com o uso de uréia, podem maximizar a 
Rev. bras. zootec.

Tabela 1 - Composição bromatológica dos alimentos (\% MS) Table 1 - Chemical composition of the feeds (\%DM)

\begin{tabular}{|c|c|c|c|}
\hline Item & $\begin{array}{l}\text { Cana-de- } \\
\text { açúcar } \\
\text { Sugar cane }\end{array}$ & $\begin{array}{c}\text { Cama de } \\
\text { frango } \\
\text { Broiler litter }\end{array}$ & $\begin{array}{c}\text { Farelo de } \\
\text { algodão } \\
\text { Cottonseed meal }\end{array}$ \\
\hline $\operatorname{MS}(\%)$ & 27,80 & 81,29 & 86,00 \\
\hline $\mathrm{PB}^{1}$ & 2,50 & 19,60 & 28,60 \\
\hline $\mathrm{MM}^{1}$ & 2,94 & 16,97 & 5,03 \\
\hline MO 1 & 97,06 & 83,03 & 94,97 \\
\hline $\mathrm{EE}^{1}$ & 0,74 & 0,45 & 1,71 \\
\hline $\mathrm{CHT}^{1}$ & 93,81 & 62,98 & 64,66 \\
\hline $\mathrm{FDN}_{\mathrm{CP}} 1$ & 57,83 & 43,47 & 28,30 \\
\hline $\mathrm{CNE}^{\mathrm{YP}}$ & 35,98 & 19,51 & 26,86 \\
\hline $\mathrm{LIG}^{2}$ & 12,00 & 10,35 & 9,87 \\
\hline $\mathrm{PIDN}^{3}$ & 18,80 & 33,67 & 5,87 \\
\hline PIDA $^{3}$ & 3,60 & 10,10 & 5,07 \\
\hline
\end{tabular}

$1 \% \mathrm{MS}(\% D M), 2 \% \mathrm{FDN}(\% N D F), 3 \% \mathrm{~PB}(\% C P)$.

MS, PB, MM, MO, FDN, CNE, LIG, PIDN, PIDA

$D M, C P, M M, O M, N D F, N E C, L I G, P I N D, P I A D$.

utilização de dietas à base de cana-de-açúcar, pelo fato destas combinações favorecerem o crescimento de bactérias utilizadoras de carboidratos estruturais e não-estruturais (SNIFFEN et al., 1992).

Os alimentos estudados destacaram-se pela elevada proporção da fração $\mathrm{B}_{2}$, sendo os valores de 71,01; 45,80; e 71,66 para cana-de-açúcar, cama de frango e farelo de algodão, respectivamente. A fração $\mathrm{B}_{2}$ é degradada em taxa intermediária no rúmen, a qual serve como fonte de aminoácidos e peptídeos tanto no rúmen, quanto no intestino delgado.

A cama de frango apresentou proporção significativa de seu nitrogênio na forma de proteína de lenta degradação $(23,57 \%)$, a qual tende a escapar do rúmen e fornecer aminoácidos no intestino delgado. A fração C da cama de frango foi elevada, provavelmente em decorrência da presença de lignina contida nos caules de capim-elefante, que serviu de substrato para produção da cama de frango. A fração C é constituída por proteínas associadas à lignina, complexos tânicosprotéicos e produtos de Maillard, os quais resistem ao ataque das enzimas microbianas e do hospedeiro, sendo, portanto, indisponíveis durante a passagem pelo trato gastrintestinal. A menor proporção da fração A $(13,72 \%$ PB) possivelmente pode ser explicada pelo tipo de metodologia utilizada na determinação. $O$ farelo de algodão apresentou $72,48 \%$ do seu conteúdo protéico como $\mathrm{B}_{2}+\mathrm{B}_{3}$, podendo ser utilizado para propiciar maior aporte de nitrogênio nos intestinos.

As taxas de degradação da fração B1 foram 96,$80 ; 151,87$; e 94,53 e da fração $B_{2} 8,75 ; 7,95$; e $5,56 \% \mathrm{~h}^{-1}$, para cana-de-açúcar, cama de frango e farelo de algodão, respectivamente (Tabela 2). Os valores de $\mathrm{B}_{1}$ obtidos da cana-de-açúcar e do farelo de algodão foram inferiores aqueles descritos na literatura (SNIFFEN et al., 1992; VAN SOEST, 1994), os quais sugeriram que as taxas de degradação de $B_{1}$ estariam em intervalos de 100 a $350\left(\mathrm{~h}^{-1}\right)$ e as taxas de $\mathrm{B}_{2}$, de 8 a $15\left(\mathrm{~h}^{-1}\right)$. Entretanto, as taxas de degradação encontradas neste estudo são oriundas de alimentos cultivados em condição tropical e, nessa situação, ocorre maior mobilização do nitrogênio presente sob a forma de proteínas solúveis para as formas insolúveis, geralmente associadas à parede celular vegetal (VAN SOEST, 1994). As diferenças podem ser ainda atribuídas ao fato de que as taxas de digestão sugeridas por SNIFFEN et al. (1992) são oriundas de incubações com Streptomyces griseus, que apresenta atividade máxima para os estudos de degradação, refletindo taxas de digestão superiores às descritas na presença de enzimas isoladas da microbiota ruminal.

As taxas de degradação da fração $\mathrm{B}_{3}$ foram 0,03 ; 0,031; e 0,09 $\mathrm{h}^{-1}$ para cana-de-açúcar, cama de frango e farelo de algodão, respectivamente. Estas menores taxas de degradação são explicadas pelo fato de a fração $\mathrm{B}_{3}$ estar associada à parede celular vegetal; conseqüentemente, pode-se inferir que esta

Tabela 2 - Valores médios do fracionamento dos compostos nitrogenados e das taxas de digestão das frações e da degradabilidade efetiva (\%) das frações protéicas $\mathrm{B}_{1}, \mathrm{~B}_{2}$ e $\mathrm{B}_{3}$

Table 2 - Means values of nitrogenous compounds fractions and fraction degradation rates and effective degradability $(\%)$ of the protein $B_{1}, B_{2}$ e $B_{3}$ fractions

\begin{tabular}{cccc}
\hline Item & $\begin{array}{c}\text { Cana-de- } \\
\text { açúcar } \\
\text { Sugarcane }\end{array}$ & $\begin{array}{c}\text { Cama de } \\
\text { frango } \\
\text { Broilerlitter }\end{array}$ & $\begin{array}{c}\text { Farelo de } \\
\text { algodão } \\
\text { Cottonseedmeal }\end{array}$ \\
\hline
\end{tabular}

Frações protéicas

(\%PB)

Proteinfractions

$(\% \mathrm{CP})$

\begin{tabular}{lrrr}
$\mathrm{A}$ & 1,50 & 13,72 & 18,28 \\
$\mathrm{~B}_{1}$ & 8,89 & 6,80 & 4,18 \\
$\mathrm{~B}_{2}$ & 71,01 & 45,80 & 71,66 \\
$\mathrm{~B}_{3}$ & 15,10 & 23,57 & 0,82 \\
$\mathrm{C}$ & 3,50 & 10,11 & 5,06 \\
\hline
\end{tabular}

Taxas de digestão

$\left(\% / \mathrm{h}^{-1}\right)$

Degradation rates

$\begin{array}{llcl}\mathrm{B}_{1} & 96,80 & 151,87 & 94,53 \\ \mathrm{~B}_{2} & 8,75 & 7,95 & 5,56 \\ \mathrm{~B}_{3} & 0,030 & 0,031 & 0,090\end{array}$

Degradação

$\left(\% / \mathrm{h}^{-1}\right)$

Degradation

\begin{tabular}{lrrr}
$\mathrm{B}_{1}$ & 1,00 & 1,00 & 1,00 \\
$\mathrm{~B}_{2}$ & 70,84 & 45,68 & 71,40 \\
$\mathrm{~B}_{3}$ & 9,06 & 14,32 & 0,67 \\
\hline
\end{tabular}


representa a maior parte das proteínas digestíveis presentes nos alimentos que irão atingir os intestinos. Dessa forma, o resíduo indigerido dessa fração $\mathrm{B}_{3} \mathrm{e}$ a fração $C$ representam a maior parte das proteínas ingeridas a serem excretadas nas fezes.

Houve considerável variação nas frações de carboidratos (Tabela 3). Nota-se que os valores para a fração $C$ foram 22,$74 ; 28,00$; e $32,64 \%$ para canade-açúcar, cama de frango e farelo de algodão, respectivamente. Esta variação confere diferenças importantes entre esses alimentos, uma vez que resulta em maior ou menor digestibilidade dos carboidratos, pois a fração $\mathrm{C}$ reflete efeito na repleção ruminal, acarretando menor disponibilidade energética, em virtude de sua característica de indigestibilidade, promovendo menor consumo potencial por unidade de tempo (VAN SOEST, 1994).

A cana-de-açúcar apresentou valor para a fração C $(22,74 \%)$, provavelmente devido ao fato de conter mais lignina em sua parede celular, conferindo maior indigestibilidade dos carboidratos estruturais deste alimento. O efeito de repleção ruminal é o tempo de renovação das frações que compõem determinado alimento, sendo logicamente aplicado aos constituintes de parede celular (VAN SOEST, 1994) e, por conseguinte, importante medida mecanicista utilizada para avaliar o efeito da FDN e suas frações sobre a retenção da digesta no rúmen (VIEIRA et al., 1997b). A cana-de-açúcar, alimento de pior qualidade nutricional, tem sido correlacionada negativamente com a ingestão de matéria seca, fato justificado pela maior fração indigestível da fibra, que seria o melhor preditor da ingestão de matéria seca, devido ao seu elevado tempo de permanência ruminal $(28,56 \mathrm{~h})$.

No entanto, a cana-de-açúcar apresenta elevada fração de componentes solúveis $(35,99 \%)$, atribuída à elevada concentração de açúcares solúveis. Poderse-ia sugerir que esta fração suporta rápido crescimento microbiano no rúmen; entretanto, devido à baixa digestão da fibra potencialmente degradável $\left(\mathrm{B}_{2}-3,41 \% \mathrm{~h}^{-1}\right)$, a qual se mostrou com significativo efeito de repleção $(6,6 \mathrm{~h})$ (Tabela 3), levaria à limitação da ingestão de matéria seca em animais de maior potencial de produção. O mesmo comportamento foi observado para a cama de frango, que, apesar de ter apresentado maior fração $B_{2}(52,49 \%)$, mostrou forte efeito de repleção ruminal. A cama de frango apresentou valor de $28 \%$ da fração C, explicada pelo fato deste alimento ter tido, como substrato, o capimelefante, o qual apresenta crescimento vegetativo rápido e, conseqüientemente, rápida deposição de
Tabela 3 - Valores médios do fracionamento dos carboidratos, das taxas de digestão especificas e dos parâmetros cinéticos da degradação da FDN

Table 3 - Means values of carbohydrates fractions, specific degradation rates and kinetic parameter of NDF degradation

\begin{tabular}{|c|c|c|c|}
\hline Item & $\begin{array}{l}\text { Cana-de- } \\
\text { açúcar } \\
\text { Sugar cane }\end{array}$ & $\begin{array}{c}\text { Cama de } \\
\text { frango } \\
\text { Broilerlitter }\end{array}$ & $\begin{array}{c}\text { Farelo de } \\
\text { algodão } \\
\text { Cottonseed meal }\end{array}$ \\
\hline
\end{tabular}

Proporções

Proportions

$\begin{array}{lllr}\mathrm{A}+\mathrm{B}_{1} & 35,99 & 19,51 & 46,36 \\ \mathrm{~B}_{2} & 41,27 & 52,49 & 21,00 \\ \mathrm{C} & 22,74 & 28,00 & 32,64 \\ \text { Lignina } & 12,00 & 10,35 & 9,87 \\ \text { Lignin } & & & \end{array}$

Lignin

Taxa de digestão

Degradation rates

$\begin{array}{llll}\mathrm{A}+\mathrm{B}_{1} & 16,28 & 10,68 & 7,58\end{array}$

$\begin{array}{lrrr}\mathrm{B}_{2} & 3,41 & 5,21 & 3,38\end{array}$

Parâmetros

Parameters

$\operatorname{Sgr}\left(\mathrm{h}^{-1}\right)$

$\mathrm{C}_{2}\left(\mathrm{~h}^{-1}\right)$

$\mathrm{p}_{2}\left(\mathrm{~h}^{1}\right)$

Dig $\mathrm{B}_{2}$

$(\% / 100)$

RRT

$\mathrm{RR}(\mathrm{U})$

$\mathrm{RR}(\mathrm{I})$

$\operatorname{RR}(\mathrm{I})$

RR(U)

0,03668
0,09885
0,101163
0,65

35,21
6,6
28,56
4,29

$\begin{array}{ll}0,0367 & - \\ 0,09667 & - \\ 0,103445 & - \\ 0,65 & - \\ & \\ 33,05 & - \\ 7,51 & - \\ 25,74 & - \\ 3,43 & -\end{array}$

polímeros estruturais nas células vegetais.

O farelo de algodão apresentou superioridade da fração $A+B_{1}(46,36 \%)$, podendo implicar em melhor adequação energética ruminal e resultar em melhor crescimento microbiano ruminal, pois este alimento apresentou também significativa fração nitrogenada solúvel. Este dado foi inferior ao encontrado por SNIFFEN et al. (1992), os quais relataram que $90 \%$ dos CNE são constituídos de amido, o que justifica o valor elevado do presente estudo em comparação ao menor teor de fibra.

A caracterização dos carboidratos não-estruturais como somatório de $\mathrm{A}_{\text {e }} \mathrm{B}_{1}$ fundamenta-se no aspecto de praticidade para cálculo de rações, para ruminantes, e no aspecto analítico, uma vez que as metodologias de determinação do amido, na maioria das vezes, não resultam em valores verossímeis e não apresentam boa repetibilidade, em função da natureza heterogênea dos tecidos vegetais (MALAFAIA et al., 1997).

As taxas de degradação para as frações de rápida utilização foram maiores para a cana-de-açúcar (Tabela 3). Durante os eventos iniciais da digestão ruminal, a fração conjunta $\mathrm{A}+\mathrm{B}_{1}$ de carboidratos é 
responsável pela maior proporção dos gases produzidos (PELL et al., 1994). As taxas de digestão específica para a fração $B_{2}$ dos alimentos estudados foram ajustadas pelo modelo de único compartimento, apresentando valores da ordem de 3,$41 ; 5,21 ;$ e $3,38 \% \mathrm{~h}^{-1}$, o que é esperado para alimentos de origem tropical. No entanto, deve ser ressaltado que a FDN pode ser constituída de polímeros heterogêneos (VAN SOEST, 1994), e a utilização desta fração pode ser realizada diferentemente pelos microrganismos ruminais.

A taxa de crescimento específico dos microrganis$\operatorname{mos} \operatorname{Sgr}\left(h^{-1}\right)$ sobre a fração $B_{2}$ não foi compatível com as taxas de degradação de primeira ordem dos compostos nitrogenados presentes na parede celular. MALAFAIA et al. (1998) encontraram duas taxas de crescimento específico dos microrganismos ruminais sobre a fração potencialmente degradável da FDN, o que permite ilustrar a natureza heterogênea deste nutriente (BEUVINK e KOGUT, 1993). Entretanto, para o sistema CNCPS, é pressuposto que a fração $B_{2}$ seja homogênea e apresente taxa única de crescimento específico.

\section{Conclusões}

Os compostos nitrogenados e as taxas de digestão variaram nos alimentos estudados. A elevada fração C dos carboidratos da cana-de-açúcar e cama de frango, em detrimento da fração $B_{2}$, acarretou maior efeito de repleção ruminal e diminuição da disponibilidade energética ao longo do trato gastrintestinal.

\section{Referências Bibliográficas}

BEUVINK, J.M.W., KOGUT, J. 1993. Modeling gas production kinetics of grass silages incubated with buffered rumen fluid. J. Anim. Sci., 71(5):1041-1046.

BRODERICK, G.A. Methodology for the determining ruminal degradability of feed proteins. In: SIMPÓSIO INTERNACIONAL SOBRE EXIGÊNCIAS NUTRICIONAIS DE RUMINANTES, Viçosa, 1995. Anais... Viçosa: UFV/DZO, 1995, p.139-176.

FOX, D.G., SNIFFEN, C.J., O'CONNOR, J.D. et al. 1992. A net carbohydrate and protein system for evaluating cattle diets III. Cattle requirements and diet adequacy. J. Anim. Sci., 70(12):3578-3596.

GONZÁLEZ, D., RUIZ, M.E., ROMERO, F. et al. 1990. Recomendaciones sobre la utilización de los métodos in vitro, in situ y enzimático en el estudio de la digestión de alimentos. Cap. 2. Análise biológico y tasa de digestión. In: RUIZ, M.E., RUIZ, A. (Eds.) Nutrición de rumiantes: guia metodológica de investigación. IICA-RISPAL, San José. p.127-139.

KOHN, R.A., ALLEN, M.S. 1995. In vitro protein degradation of feeds using concentrated enzymes extracted from rumen contents. Anim. Feed Sci. Techn., 52(3):15-28.

KRISHNAMOORTHY, U., SNIFFEN, C.J., STERN, M.D. et al. 1983. Evaluation of a mathematical model of rumen digestion and an in vitro simulation of rumen proteolysis to estimate the rumen-undegraded nitrogen content of feedstuffs. Br. J. Nutr., 50(2):555-568.

LICITRA, G., HERNANDEZ, T.M., VAN SOEST, P.J. 1996. Standardization of procedures for nitrogen fractionation of ruminant feeds. Anim. Feed Sci. Techn., 57:347-358.

(Atualizar esta referência)MALAFAIA, P.A.M., VALADARES FILHO, S.C., VIEIRA, R.A.M. 1998. Kinetic parameters of ruminal degradation estimated with a non-automated system to measure gas production. Lvstck. Prod. Sci. (no prelo).

MALAFAIA, P.A.M., VALADARES FILHO, S.C., VIEIRA, R.A.M. 1997. Determinação e cinética ruminal das frações protéicas de alguns alimentos para ruminantes. R. Bras. Zootec., 26(6):1243-1251.

MALAFAIA, P.A.M., VIEIRA, R.A.M. Técnicas de determinação e avaliação dos compostos nitrogenados em alimentos para ruminantes. In: SIMPÓSIO INTERNACIONAL DE DIGESTIBILIDADE EM RUMINANTES, Lavras, 1997. Anais... Lavras: FAEPE, 1997, p.29-54.

MERTENS, D.R. 1993. Kinetics of cell wall digestion and passage in ruminants. Chap. 21. In: JUNG, H.G., BUXTON, D.R., HATFIELD, R.D. et al. (Eds.) Forage cell wall structure and digestibility. Madison, Wisconsin: American Society of Agronomy. p.535-570.

NATIONAL RESEARCH COUNCIL - NRC. 1996. Nutrients requirements of beef cattle. 7. Revised Ed., Washington, D.C.: National Academy Press. 242p.

PELL, A.N., SCHOFIELD, P. 1993. Computerized monitoring of gas production to measure forage digestion in vitro. J. Dairy Sci., 76(9):1063-1073.

RUSSELL, J.B., O'CONNOR, J.D., FOX, D.G. et al. 1992. A net carbohydrate and protein system for evaluating cattle diets: I. Ruminal fermentation. J. Anim. Sci., 70(12):3551-3561.

SCHOFIELD, P., PITT, R.E., PELL, A.N. 1994. Kinetics of fiber digestion from in vitro gas production. J. Anim.Sci., 72(11):2980-2991.

SNIFFEN, C.J., O'CONNOR, J.D., VAN SOEST, P.J. et al. 1992. A net carbohydrate and protein system for evaluating cattle diets: II. Carbohydrate and protein availability. J. Anim. Sci., 70(12):3562-3577.

UNIVERSIDADE FEDERAL DE VIÇOSA - UFV. 1995. Sistema de análises estatísticas e genética-SAEG. Viçosa, MG: UFV. (Apostila).

VAN MILGEN, J., MURPHY, M.R., BERGER, L.L. 1991. A compartmental model to analyze ruminal digestion. J. Dairy Sci., 74(9):2515-2529.

VAN SOEST, P.J. 1994. Nutritional ecology of the ruminant. 2.ed., New York, Ithaca: Cornell University Press. 476p.

VAN SOEST, P.J., ROBERTSON, J.B., LEWIS, B.A. 1991. Methods for dietary fiber, neutral detergent fiber, and nonstarch polyssacharides in relation to animal nutrition. J. Dairy Sci., 74(10):3583-3597.

VIEIRA, R.A.M. Simulação da dinâmica de nutrientes no trato gastrintestinal: aplicação e validação de um modelo matemático para bovinos a pasto. Viçosa MG: UFV, 1998. $91 \mathrm{p}$. Tese (Doutorado em Zootecnia) - Universidade Federal de Viçosa, 1998.

VIEIRA, R.A.M., PEREIRA, J.C., MALAFAIA, P.A.M. et al. 1997b. The influence of elephant-grass (Pennisetum purpureum Schum., Mineiro variety) growth on the nutrient kinetics in the rumen. Anim. Feed Sci. Techn., 67:151-161.

Recebido em: 08/02/00 Aceito em: 09/08/00 